\title{
A Study of Investigation Method upon Expressway Service Level
}

\author{
Runmou Xiao \\ School of Automotive Engineering \\ Chang'an University \\ Xi'an China \\ xrm@chd.edu.cn
}

\author{
Shengyu Yan \\ School of Automotive Engineering \\ Chang'an University \\ Xi'an China \\ leo9574@163.com
}

\begin{abstract}
The survey of expressway service level in China awaits upgrading nowadays. This artide proposes that respondents herein cover drivers of travelers and goods transport, trans port managerial, passengers, sedan drivers etc, in the view of consumers of road commodity networking. And the respondent weight is determined by questionnaire numbers and difficulty level for sample taking. The preliminary survey, proceeded with on-the-spot questionnaire and discussions with transport enterprises, suggests a focus of investigation upon consummation and satisfaction of services in transit, toll station, traffic information, along with placement of service area and its parking lot, and customer convenience. Finally, a survey cost forecasting model is put forward, according to the optimal allocation out of stratified sampling, and the stratified sample size is affirmed. Namely, the response rate renders the bulk sample coordination. The proposed investigation measure provingly reveals the factual expressway service status, based on its low cost, high availability and easy usage. 4 tabs, 1 fig, 5 refs.
\end{abstract}

Keywords- Traffic Transport; Expressway; Service Level; Questionnaire; Sample Size

\section{INTRODUCTION}

In the end of 2011, China's expressway mileage open to traffic amounted to $84,946 \mathrm{~km}$, up $14.62 \%$ YoY (Ministry of Transport of China, 2011). The high speed construction and transportation have diversified the expressway service market, customer demands and operational management. Their performance accordingly like intermingled service levels, feeble service consciousness, incomplete facilities, lower client satisfaction is restricting the standardization of express way service. These bring in complexity of service quality evaluation, and even local expressway managements have difficulties in horizontal comparison.

The entire service level survey and evaluation system rely on on-the-spot investigations. The respondents shall count mainly in expressway service clients, such as passenger drivers, teamsters, transport enterprise managerial, passengers, car drivers etc. And, the survey takes interviews and discussions with transport enterprises, along with questionnaires for its understandability, short survey time, and easy operation. Such method also lowers survey cost and raises efficiency.

\section{PRELIMINARY SURVEY}

Preliminary survey, in a small sample size, enables the inquirers to acquire the real previously, and check up validity of the questionnaires.

The questionnaires, on the basis of conciseness and mechanics, are composed of combinations of single and multiple questions close to the survey theme. Question numbers are arranged rationally in due quantity, avoiding some sensitive topics like inquiry of driver's name or his experienced traffic accident.

\section{A. Determination of sample composition}

The respondents at passenger transport center include passengers and drivers, and at transport enterprises drivers and managerial. In express way service areas, objects cover the maximum, including all drivers and passengers there. There exist differences among the survey subjects and the corresponding objects, as shown in Table 1 .

TABLE I. CORRELATION BETWEEN THE SUBJECTS AND OBJECTS

\begin{tabular}{cc}
\hline Subjects & Objects \\
\hline Shipping enterprise & Teamsters, management personnel \\
Passenger transports & Bus drivers, management personnel \\
enterprise & Bus drivers, passengers \\
Passenger station & Teamsters, bus drivers, car drivers, \\
passengers
\end{tabular}

The survey of objects to be divided upon theme correlations is purposed to make for resultant reliability. Passenger drivers are in both passenger transport stations and pass enger trans port companies, the same to managerial personnel in shipping companies and passenger transport companies, which ensure the sample proportions for all subjects within control. Therefore, the object weight can be determined according to question numbers in questionnaire, subjects and object correlations, and difficulty levels for object survey(Xiao-chun LU e.g., 2003). The weights allotted to all objects are shown in Table 2.

TABLE II. WEIGHT FOR SURVEY OBJECTS

\begin{tabular}{ccccc}
\hline Teamsters & Bus drivers & Passengers & Managers & Car drivers \\
\hline 0.3 & 0.3 & 0.15 & 0.1 & 0.15 \\
\hline
\end{tabular}


Expressway drivers are key survey points at their first hand perception for service quality, in comparison with managers in transport enterprises. They get in more touch than passengers with variety of service items and long service time, such as manner of toll collectors, consistency of traffic sign settings etc. Good representatives as they are drivers can be regarded as weatherglass, reflecting actual service level on expressways, except for relative difficulty in car driver surveying, as they are mostly none-business operational, staying short at toll station and service area(Bureau of Transportation Statistics, 2011). That results in their low weight. In 2011, freighters with 3 and more axis take $57.72 \%$ of its general quantity on expressways in China. Their longer average haulage, and regular crossing over various regions, compared to light trucks, provided comprehensive and detailed service status in different provinces.

Passengers, closely relevant to service area though, are not concerned directly about services on toll station, traffic information and transit. They may pay attention to the length of traffic jam or road seal owing to pavement works, but not to traffic conditions or consistency of transit diversion signs. Large sample size is hence required to approach the survey accuracy, in view of the large cardinal at passenger trans port stations and service areas.

Transport managerial personnel, as indirect beneficial owners from expressway service, are entitled to score the quality, but share low weight because of its interest tendency and small sized cardinal.

\section{B. Content of investigation}

There are 4 dimensionalities adopted for service level evaluation, including services in toll station management, service area, parking area, and traffic information. See in Table 3.

TABLE III. SCOPE OF SURVEY ON OPERATIONAL SERVICE LEVEL

\begin{tabular}{|c|c|}
\hline Scope of inquiry & Content \\
\hline Transit service & $\begin{array}{l}\text { Pavement satisfaction, measures for } \\
\text { conservation work, tunnel valuation, } \\
\text { valuation on trailing rescue, valuation on } \\
\text { reasonableness and consistency of traffic } \\
\text { signs and markings etc. }\end{array}$ \\
\hline Toll station service & $\begin{array}{l}\text { Average waiting time, manner valuation, } \\
\text { ETC advices, valuations on weighting device } \\
\text { precision, overload checkup service etc. }\end{array}$ \\
\hline $\begin{array}{c}\text { Traffic } \\
\text { information service }\end{array}$ & $\begin{array}{l}\text { Information source, dat a receipt validity and } \\
\text { promptness, feasibility of pay information, } \\
\text { service progress advices etc. }\end{array}$ \\
\hline $\begin{array}{l}\text { Service in service } \\
\text { area }\end{array}$ & $\begin{array}{l}\text { Satisfaction among service facilities, } \\
\text { commodity prices, facility maturity, survey } \\
\text { on driver and passenger behavior etc. }\end{array}$ \\
\hline
\end{tabular}

Among different objects, survey scope and method vary, such as, no questions toward passengers about weight precision. Different objects are subject to different questions in arrangement available for site investigation.

\section{Questionnaire consummation}

A functional questionnaire counts on good consideration of practical situations, such as occurrence of some uncertainties or potential subjective notions from respondents during preliminary and spot investigations. That suggests the method not to adopt only optional or scaled questionnaires, but leave sufficient space for clients' subjective ideas. After the preliminary survey, a new questionnaire and symposium plan are to be upgraded on the principle of practicability, speed and high efficiency.

\section{Questionnaire consummation}

An evaluation system, fairly, equally and impersonally, are purposed to accelerate expressway service surveillance and management. Factors as maneuverability and comparability are herein taken into account in its designing.

Client satisfaction measures acceptance of service levels. Items are added in as highly satisfied, fairly satisfied, not satisfied, and highly unsatisfied, which may unlikely arouse repulsions. Satisfaction items are placed in the front, guiding the objects into inquiry quickly for questions, like satisfaction degrees toward toll collector manners. Maneuverability can be reached.

The mentioning amount on expressway service functions reflects its actual rate of utilization, such as usage of ETC lane, weighting device precision and reliability, etc. The higher functions are mentioned, the more concerns it receives in some given region. The key region for service enhancement emerges.

The quantizing index of average service level from client feedback, like average waiting time, commodity prices in service area etc., embodies the actual situation on the stage, coupled with respondent weight. Accordingly, the client acceptance limit makes clear of service status and derives reas onable measurement.

\section{METHOD OF INVESTIGATION}

Before you begin to format your paper, first write and save the content as a separate text file. Keep your text and graphic files separate until after the te xt has been formatted and styled. Do not use hard tabs, and limit use of hard returns to only one return at the end of a paragraph. Do not add any kind of pagination anywhere in the paper. Do not number the text heads - the template will do that for you.

Finally, complete content and organizational editing before formatting. Please take note of the following items when proofreading spelling and grammar:

\section{A. Train of thought}

Based on the information feedback from the main target of service in preliminary investigation, including passenger and goods drivers, managerial, passengers, car drivers etc., the spot survey accepts questionnaire and discussions with transport enterprises. The survey proceeds with the 4 dimensionalities as management of toll stations, service in service and parking areas, and transit service (Wei ZHOU \& Bing-gang WANG, 2001). The statistics are taken as quantitative index from client satisfaction, response rate, charge-waiting time, commodity prices in service area etc. Meanwhile, discussions with clients upon service satisfaction and consummation are carried out, and the individual suggestions are given great consideration in sample collection, such as parking area to be extended, charge screen display to be completed, ETC vehicle to be highly recognized, problems in real time recording, and management gaps etc. Furthermore, survey independency of expressway runners shall reveal real service status. 


\section{B. Determination of sample size}

With respect to the given precision and confidence level, the bigger the population variance, the bigger the sample size needed, and the higher the inquiry cost. If the population is composed of several independent parts with big difference, and there exists consistency between the population and samples, the variance of each stratification under stratified sampling method tends to be less than the population, and much less than the sample capacity under none stratified sampling. This indicates both research cost decreasing and efficiency lifting.

At the premise of given sampling precision, the lowest sample capacity is reckoned in the following formula (William \& Terry, 2009).

$$
\begin{gathered}
W_{h}=\frac{N_{h}}{N}=\frac{n_{h}}{n}=w_{h} \\
n=\frac{\sum \frac{W_{h} \cdot S_{h}^{2}}{w_{h}}}{\left(\frac{r \cdot \bar{Y}}{t}\right)^{2}+\frac{\sum W_{h} \cdot S_{h}^{2}}{N}}
\end{gathered}
$$

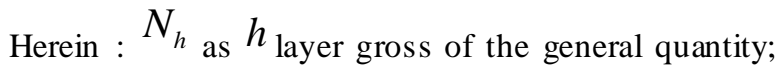
$n_{h}$ as $h$ layer gross of the samples; $N$ as the general quantity; $w_{h}$ as $h$ layer weight of the samples; $W_{h \text { as }} h$ layer weight of the population; $S_{h}^{2}$ as $h$ layer variance of the population; $n$ as the lowest sample gross to be fixed; $r$ as relative error of sampling; $\bar{Y}$ as ensemble average; $t$ as bilateral quantile of the standard normal distribution, and the confidence as $95 \%$.

A simple linear cost function can be taken to reach the optimu $\mathrm{m}$ allocation of the stratified sample size for lowest total cost.

$$
C=C_{0}+\sum_{h=1}^{L} C_{h} \cdot n_{h}
$$

Herein: $C_{0}$ as fixed expense, including travel expenses from investigators and items of indirectly input for spot investigations; $C$ as an average unit expense drawn from $h$ layer.

Herein : $N_{h}$ as $h_{\text {layer gross of the general quantity; }}$ $n_{h}$ as $h$ layer gross of the samples; $N$ as the general quantity; $w_{h}$ as $h$ layer weight of the samples; $W_{h}$ as $h$ layer weight of the population; $S_{h}^{2}$ as $h$ layer variance of the population; $n$ as the lowest sample gross to be fixed; $r$ as relative error of sampling; $\bar{Y}$ as ensemble average; $t$ as bilateral quantile of the standard normal distribution, and the confidence as $95 \%$.
A simple linear cost function can be taken to reach the optimu $\mathrm{m}$ allocation of the stratified sample size for lowest total cost.

$$
C=C_{0}+\sum_{h=1}^{L} C_{h} \cdot n_{h}
$$

Herein: $C_{0}$ as fixed expense, including travel expenses from investigators and items of indirectly input for spot investigations; $C$ as an average unit expense drawn from $h$ layer.

\section{Response rate}

As index reflection of sample group cooperate degree and forecast input cost, the response rate affects the representativeness upon the general population from the samples. And the response rate educed from questionnaire number weighting lays out the real difficulty level of the inquiry performance. The weighted response rate is shown in the following formula:

$$
\begin{gathered}
\bar{P}_{i}=\frac{\sum_{j=1}^{n} R_{i j}}{Q_{i} \cdot \sum_{j=1}^{n} Y_{i j}} \\
\bar{P}_{k}=\frac{\sum_{j=1}^{n} R_{k j}}{\sum_{k=1}^{m} Q_{k} \cdot Y_{k j}}
\end{gathered}
$$

Herein: $\bar{P}_{i}$ as average response rate from $i$ questionnaire, namely, the response rate of the respondents; $\bar{P}_{k}$ as average response rate upon $k$ item; $i$ as questionnaire category; $j$ as responder; $R_{i j}$ as actual response from the respondents; $i$ as question numbers in $i$ questionnaire; $R_{k j}$ as actual question numbers upon $k$ item by the respondents; $Q_{i}$ as question numbers in $i$ questionnaire; $Q_{k}$ as question numbers in $k$ item; $Y_{i j}$ as No. $j$ responder for $i$ questionnaire; $Y_{k j}$ as NO. $j$ responderfor $k$ item.

\section{EXAMPLE ANALYSIS}

In the end of 2011, a large sized and all-round investigation was initiated upon the expressway service level in China. 7066 samples and 2 response calculations work out the average response rate as shown in Table 4. 
TABLE IV. AVERAGE RESPONSE RATE

\begin{tabular}{cccc}
\hline respondents & $\begin{array}{c}\text { Average } \\
\text { response rate }\end{array}$ & Inquiry item & $\begin{array}{c}\text { Average } \\
\text { response } \\
\text { rate }\end{array}$ \\
\hline Freight drivers & $92.18 \%$ & Transit service & $93.93 \%$ \\
Bus drivers & $81.26 \%$ & $\begin{array}{c}\text { Total station } \\
\text { Traffic }\end{array}$ & $84.55 \%$ \\
Car drivers & $87.68 \%$ & $\begin{array}{c}\text { information } \\
\text { Service and } \\
\text { parking areas }\end{array}$ & $83.12 \%$ \\
Bus passengers & $89.61 \%$ & Ex- & - \\
$\begin{array}{c}\text { Transport } \\
\text { enterprise } \\
\text { managerial }\end{array}$ & $93.75 \%$ & & \\
\hline
\end{tabular}

The inquiry target focuses mainly on drivers for their direct participation and close contact with expressway transit and service, $71.23 \%$ of the general sample size. Of its composition after selection out of valid data are shown in Fig. 1.

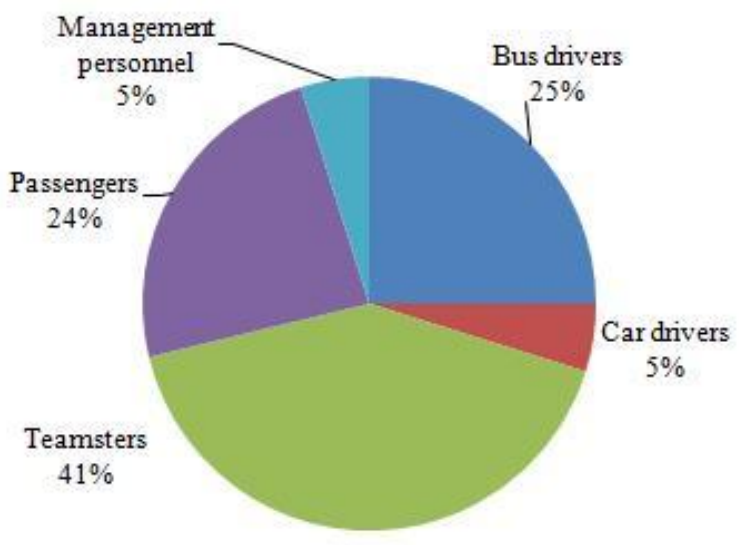

Figure 1. Object Sample Composition

Under undesirable conditions, the consummated questionnaire is capable of quick response, reflecting availably the service level and management gaps during expressway operation. It also features in its low survey expense, high effectiveness, and simplicity, and in its non- pulsion by the respondents. A real expressway service is to be approached.

\section{CONCLUSION}

Preliminary inquiry is indispensable, which works closely to the fact and improves the survey plan at principle of locality, simple modal and integration. The formal spot investigation shall evade disturbance from the expressway management, favorable for the investigation reliability.

Stratified sampling is taken for sample capacity determination, while all stratified weight differences under optimum allocation and average survey cost are all taken into account. It indicates that, the less the sample individuation of each stratification is, the less the expenses for each survey will be.

An inquiry scheme for expressway service level is brought forward. And it proves feasible and practicable by large scope of spot investigation and verification. This research may be theoretical for standardization of expressway service, and directive for further study on client behavior and service on expressways.

\section{REFERENCES}

[1] Dept. of Comprehensive Planning, Ministry of Transport of China. (2011). Statistics and Analysis Report of Freeway for China in 2011. Beijing: China Communication Press.

[2] Xiao-chun LU, Jin-song WANG, Zi-gang YAN, Ming-hui LI, Hua LIANG. (2003). Service evaluation system for expressway operation. Journal of Chang'an University(Natural Science Edition), 23, 68-72.

[3] U.S. Department of Transportation, Research and Innovative Technology Administration, \& Bureau of Transportation Statistics. (2011). National Transportation statistics 2011. Washington D.C.: Bureau of Transportation Statistics.

[4] Wei ZHOU, Bing-gang WANG. (2001). Study of the principles and methods for determining LOS and service traffic volume, China Journal of Highway and Transport, 14, 90-95.

[5] William Mendenhall, Terry Sincich. (2009). Statistics for Engineers and the Sciences. London: Person Hall. 